\title{
The influence of electrical stress on the distribution of electrically active defects in IGBT
}

\author{
J. Drobný ${ }^{1}$, J. Marek ${ }^{1}$, A. Chvála ${ }^{1}$, J. Faraga ${ }^{1}$, M. Jagelka ${ }^{1,2}$, and L. Stuchlíková ${ }^{1}$ \\ ${ }^{1}$ Institute of Electronics and Photonics, Slovak University of Technology in Bratislava \\ Bratislava, Slovakia \\ ${ }^{2}$ POWERTEC, s.r.o, \\ Bratislava, Slovakia
}

\begin{abstract}
This paper highlights electrically active defects investigation of the sixth generation $1200 \mathrm{~V}$ trench stop silicon-based Insulated Gate Bipolar Transistors by Deep Level Transient Fourier Spectroscopy. The focus is on the impact of electrical stress on defects distribution in the studied structures. Five electronlike deep energy levels ET1 $(0.126 \mathrm{eV})$, ET2 $(0.188 \mathrm{eV})$, ET3 $(0.322 \mathrm{eV})$, ET4 $(0.405 \mathrm{eV})$, and ET5 $(0.514 \mathrm{eV})$, and nine hole-like deep energy levels HT1 (0.187 eV), HT2 (0.231 eV), HT3 (0.246 eV), HT4 (0.301 eV), HT5 (0.319 eV), HT6 (0.327 eV), HT7 (0.529 eV), HT8 (0.534 eV), and HT9 $(0.750 \mathrm{eV})$ were identified. The presence of unintentional impurities like zinc, platinum, gold, etc. and emissions from structural imperfections was confirmed. A significant increase of the defect concentration after electrical stress in the temperature range of 120 to $225 \mathrm{~K}$ has been detected. Electrical stress did not affect the defect concentration above temperature $300 \mathrm{~K}$.
\end{abstract}

Keywords: IGBT, deep energy levels, electrically active defects, the impact of electrical stress, Deep Level Transient Fourier Spectroscopy.

\section{INTRODUCTION}

The development of innovative silicon-based power semiconductors devices with increased power density and energy efficiency is a challenge for an advanced industry 4.0. These devices provide the performance of a large number of applications, with a focus on industry, mobility, grid and renewable energy [1]. Together, they will contribute to reducing carbon dioxide emissions despite the world's ever-increasing energy needs [2]. This is consistent with one of the objectives of the European Commission, which wants the EU to lead the clean energy transition. For this reason, the EU has committed to cut $\mathrm{CO}_{2}$ emissions by at least $40 \%$ by 2030 [3].

Silicon-based power solutions are well known for decades [4]; however, the demand for the highest energy efficiencies are growing. Based on new materials, like gallium nitride, and silicon carbide [5], [6], the highest efficiencies have been shown recently, and production of those devices has started and will increase. Widely established silicon outcompetes upcoming new materials like $\mathrm{GaN}$ and $\mathrm{SiC}$ for power electronics because of its high reliability and excellent performance-price ratio (Figure 1).
IGBT power transistors have an irreplaceable role in power electronics circuits. The silicon-based IGBT has become widely accepted as the power device of choice for medium and high-power applications where the circuit operating voltages exceed $200 \mathrm{~V}$ [7]. It has enabled the development of highly efficient adjustable speed motor drives for industrial applications, compact fluorescent lamps for lighting, and an electronic ignition system for transportation [8]. During their operation, these components are exposed to extreme electrical stress, so it is desirable to ensure high stability of the distribution of electrically active defects for the correct operation of these components.

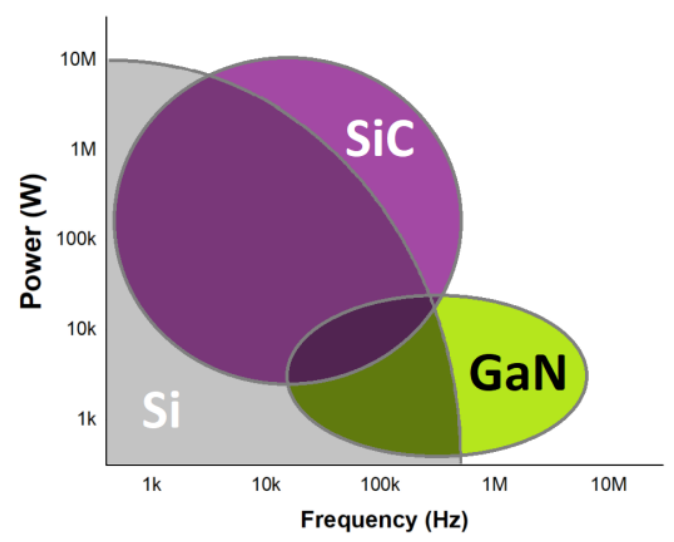

Figure 1: Comparison of technologies (inspired by [9]) 
The presence of electrically active defects in semiconductor devices can negatively impact the operation of these devices. These defects represent deep energy levels in the forbidden band of the semiconductor, which behave as capture or recombination centres. They are most of the time direct sources of material degradation, undesired electrical, optical or even structural properties. For example, after capturing the free carrier in such a capture centre, this localised charge carrier will no contribute to the current, and the carrier lifetime will be shortened. A carrier lifetime is a key physical property, which determines the on-state and switching characteristics of bipolar devices. It can cause slower switching during switching processes but also make the whole system inoperable. Even small concentrations of unwanted electrically active defects can significantly affect the performance and reliability of IGBTs. Defect identification and control has always been one of the essential tasks in the development of electronic devices and to optimise the fabrication process [10].

Deep Level Transient Spectroscopy (DLTS) is one of the essential methods of electrical active defect identification [11]. The values of the fundamental parameters governing thermal emission and capture on a deep energy level - activation energies $\Delta E_{T}$ and capture cross sections $\sigma_{T}$ were calculated from an Arrhenius diagram [12]. It is a high-frequency capacitance transient thermal scanning method in which an electrical excitation pulse causes the capacitance transient effect in the potential barrier of the semiconductor. Although DLTS satisfies basic diagnostics requirements, e.g. non-destructivity and sensitivity, like other techniques, it has its limitations. The most challenging part of such investigation is the interpretation of experimental results [13]. Different factors are needed to be taken into account to establish a reliable evaluation procedure. On the one hand, we can have a comprehensive and reliable measurement result, although on the other, a non-evaluable experiment. In some cases, the opposite is true, deep energy level parameters (activation energy $\Delta E_{\mathrm{T}}$, capture cross-section $\sigma_{\mathrm{T}}$ and the trap concentration $N_{\mathrm{T}}$ ) are obtained with high reliability, but structural and geometrical properties are indicating a questionable investigation.

The method's accuracy is mainly affected by complex situations in which different deep energy levels are interacting; therefore, the utilisation of different defectrecognition techniques and analytical approaches is a crucial factor of accuracy. We focus on one of the digital DLTS modifications, the DLTFS (Deep Level Fourier Transient Spectroscopy) method [14]. DLTFS is a digital system that records the whole capacitance transients and transfers the data into a computer system. Using a Fourier transformation and direct evaluation of the Fourier coefficients, the time constant and the transient amplitude can be evaluated for every transient measured at any temperature. Only one temperature cycle is necessary to measure the activation energy of a deep energy level. This modification was developed according to the increasing need for high sensitivity, reliability and accurate results.

This paper introduces the DLTFS study of electrically active defects in $1200 \mathrm{~V}$ silicon-based IGBT power transistors prepared by the sixth generation trench stop IGBT technology. This study was realised with the aim to contribute to investigate the impact of electrical stress on the distribution of defects in the measured structures.

\section{EXPERIMENT}

IGBT power transistors used in this DLTFS study are $1200 \mathrm{~V}$ silicon-based trench gate/field-stop IGBTs. This first $1200 \mathrm{~V}$ discrete IGBT in $300 \mathrm{~mm}$ was prepared by the sixth generation trench stop IGBT technology. It is optimised for low switching losses in hard switching and resonant topologies operating at switching frequencies above $15 \mathrm{kHz}$. Its typical structure is illustrated in Figure 2 left, and key performance parameters are listed in Table 1. The examined samples were exposed to electrical stress: pulse width $3 \mu \mathrm{s}$, drain voltage $600 \mathrm{~V}$, the gate voltage $15 \mathrm{~V}$, current $100 \mathrm{~A}$ and number of pulses 200 thousand. Three sets of DLTFS measurements were realised: before electrical stress (structure labelled no stress), after the stress (structure labelled stress 1) and after the repeated stress (structure labelled stress 2).

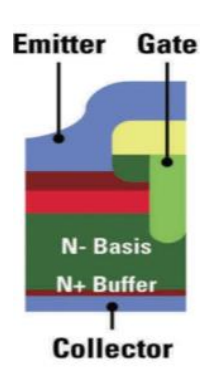

GEN 6

Field-stop

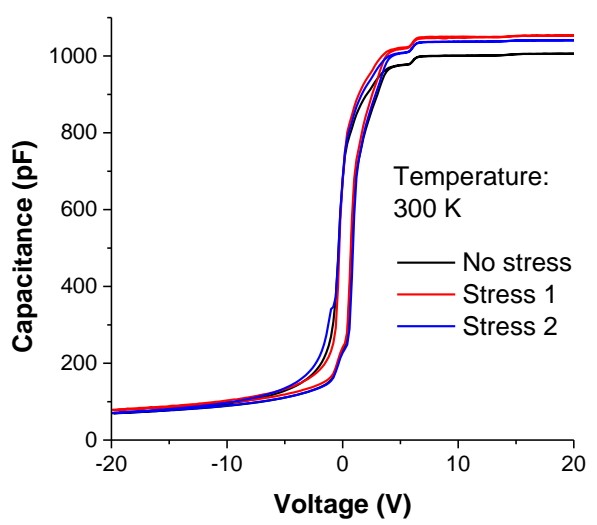

Figure 2: a) Silicon cross-section of a trench IGBT [15] and $\mathrm{b}$ ) measured $\mathrm{CV}$ on the examined IGBT structures

\begin{tabular}{|c|c|c|}
\hline Parameter & Symbol & Value \\
\hline Collector-emitter voltage & $V_{\mathrm{CE}}$ & $1200 \mathrm{~V}$ \\
\hline DC collector current & $I_{\mathrm{C}}$ & $15 \mathrm{~A}$ \\
\hline $\begin{array}{l}\text { Collector-emitter } \\
\text { saturation voltage } \\
\text { Operating iunction }\end{array}$ & $V_{\text {CEsat }}$ & $1.9 \mathrm{~V}$ \\
\hline temperature & $T_{\mathrm{vj}}$ & $-40 \ldots+175^{\circ} \mathrm{C}$ \\
\hline
\end{tabular}

Table 1: Key performance parameters of the studied IGBT 
Figure 2 right shows characteristic $\mathrm{C}-\mathrm{V}$ measured on the examined IGBTs before and after electrical stress. The DLTFS measurements were carried out in the temperature range from 80 to $550 \mathrm{~K}$ using the BIORAD DL8000 measuring system equipped with Fourier transform analysis of the measured capacitance transients. The signal frequency for capacitance measurements is $1 \mathrm{MHz}$, and the magnitude of the applied differential voltage is $30 \mathrm{mV}$. During the measurements, the reverse bias was set at different voltages and periodically pulsed to the fill voltage to ensure trap filling. The voltages were applied between IGBT terminals Gate and Collector. DL8000 workplace displayed the majority charge defects as positive peaks and the minority charge defects as negative peaks [14]. The obtained DLTFS spectra were evaluated using the Fourier transform analysis with the "Direct Arrhenius evaluation" option.

\section{RESULTS AND DISCUSSION}

DLTFS experiments confirmed the presence of several emission and capture processes (Figure 3-8). Five electron-like deep energy levels and nine hole-like deep energy levels were identified. Defect parameters compared with parameters in references [16-23] are presented in Table 2. These identified defects most likely belong to the impurities of the chemical elements. Unintentional incorporation of impurities like zinc, gold, nickel, vanadium, silver, manganese and platinum are common contaminants in the growth systems typical for silicon-based devices. References for the identified defects presented in Table 2 are available in the defect catalogue/library at the DL8000 workplace. However, the origin of the identified defects may not correspond to the reference levels from the defect catalogue closest to the position. Due to the atypical behaviour of DLTFS spectra at temperatures lower than $250 \mathrm{~K}$, it is possible to assume that the disturbances in DLTFS signal for defects ET1, ET2, HT1, and HT2 may correspond to the emission from structural imperfections like vacancies, resp. A - centre, corresponding to the vacancy-oxygen center [24].

Figures 3 depict measured DLTFS spectra under the different measurement conditions in all three types of examined structures with evaluated 5 electron-like deep energy levels with the activation energies and the positions in the DLTFS spectra. Defects ET1 $(0.126 \mathrm{eV})$, ET2 $(0.188 \mathrm{eV})$, and ET5 $(0.514 \mathrm{eV})$ were identified in all three types structures. Defects ET3 $(0.322 \mathrm{eV})$ and ET4 $(0.405 \mathrm{eV})$ were identified only in structures after stress (stress 1 and stress 2).

Typical measured DLTFS spectra only for minority defects are shown in Figure 4. Nine hole-like deep energy levels HT1 (0.187 eV), HT2 (0.231 eV), HT3 (0.246 eV), HT4 (0.301 eV), HT5 (0.319 eV), HT6 (0.327 eV), HT7 (0.529 eV), HT8 (0.534 eV), and HT9

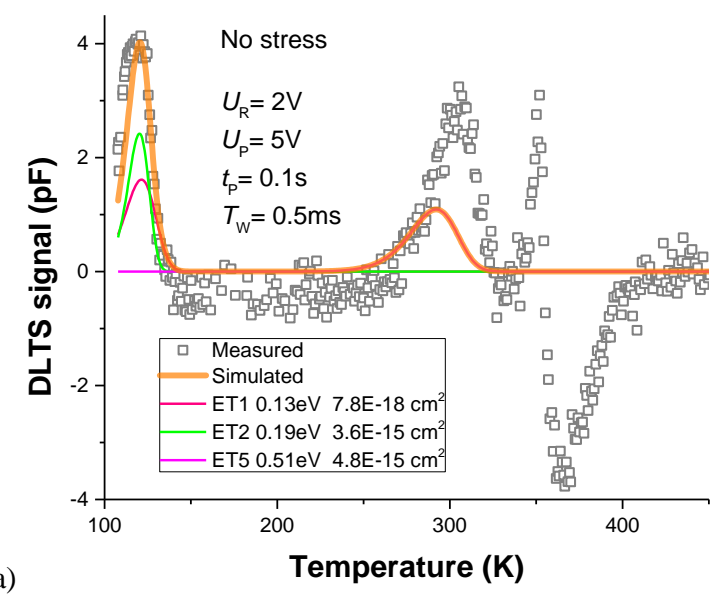

a)

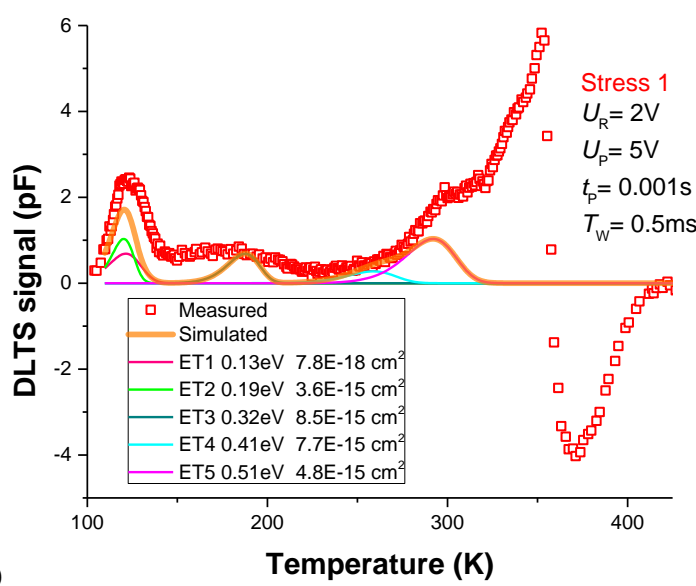

b)

Temperature (K)

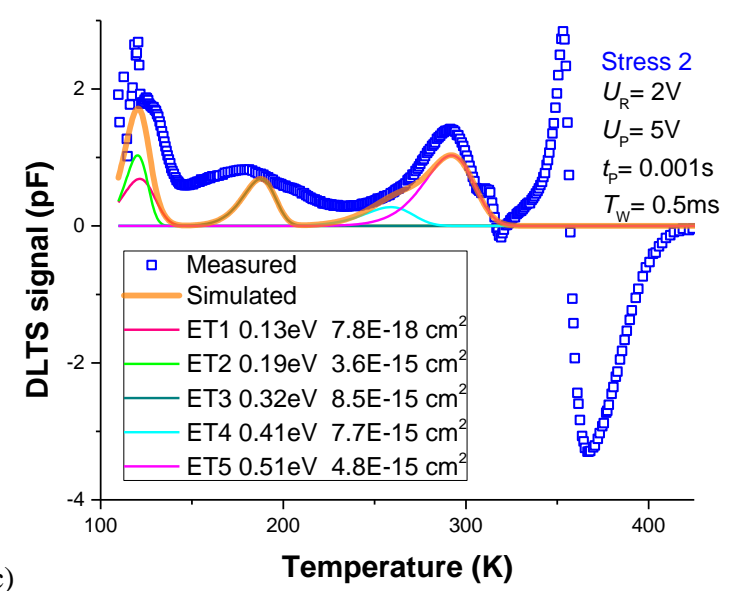

Figure 3: Identified electron-like defects, measured and simulated DLTFS spectra.

$(0.750 \mathrm{eV})$ were identified in all three investigated structures. It is possible to observe significant changes in the peak heights of DLTFS signals corresponding to the identified defects.

The Arrhenius plots in the Figure. 5/ Figure 6 show all the evaluated electron-like/hole-like deep energy levels with their activation energies and reference deep energy levels with activation energies from the defect library for silicon. The effective mass of electrons and holes in silicon were respected in the DLTFS. 

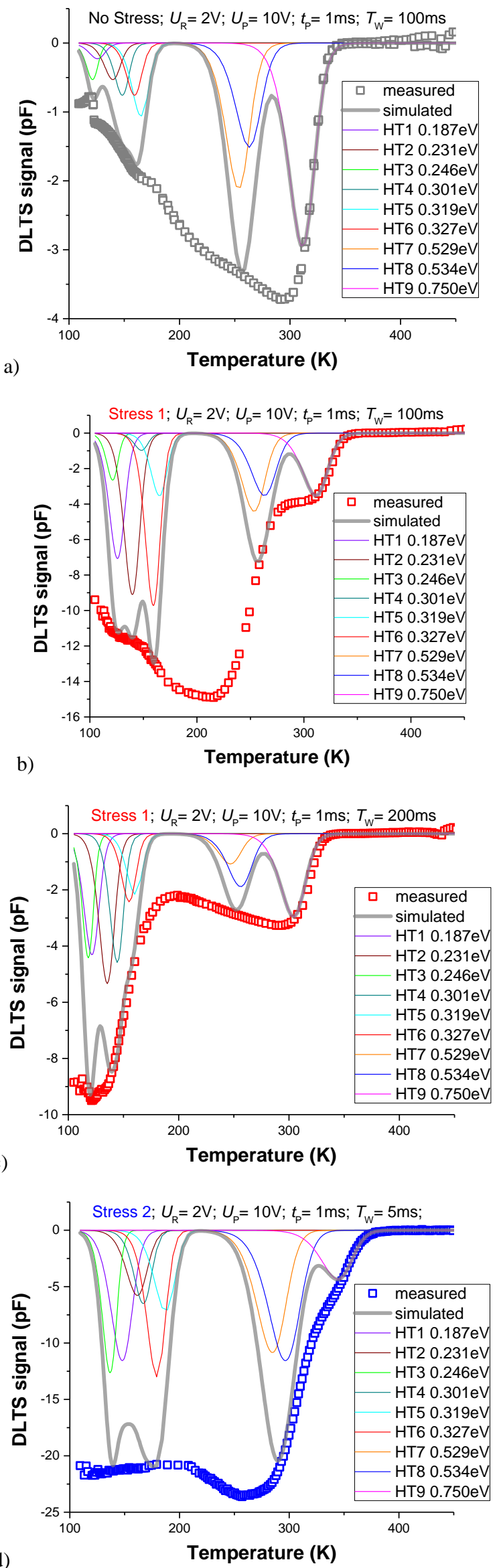

Figure 4: Identified hole-like defects, measured and simulated DLTFS spectra

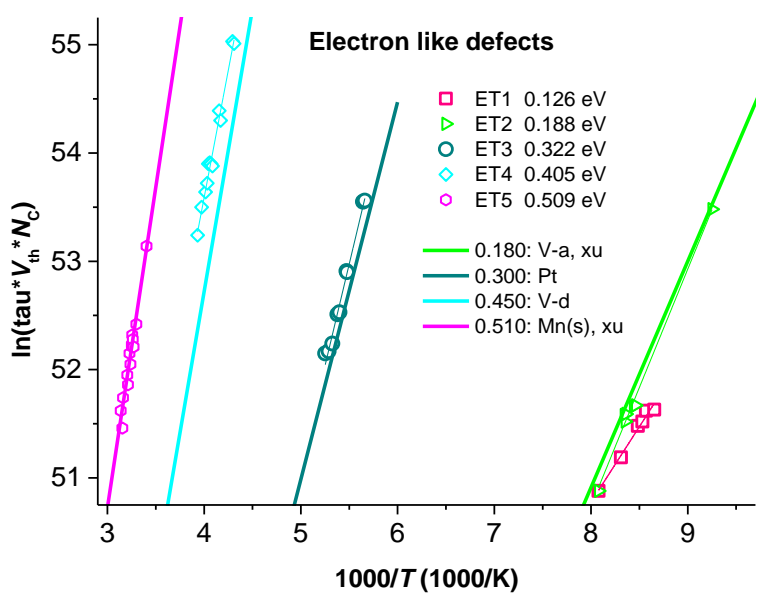

Figure 5: The Arrhenius plot of electron like defect

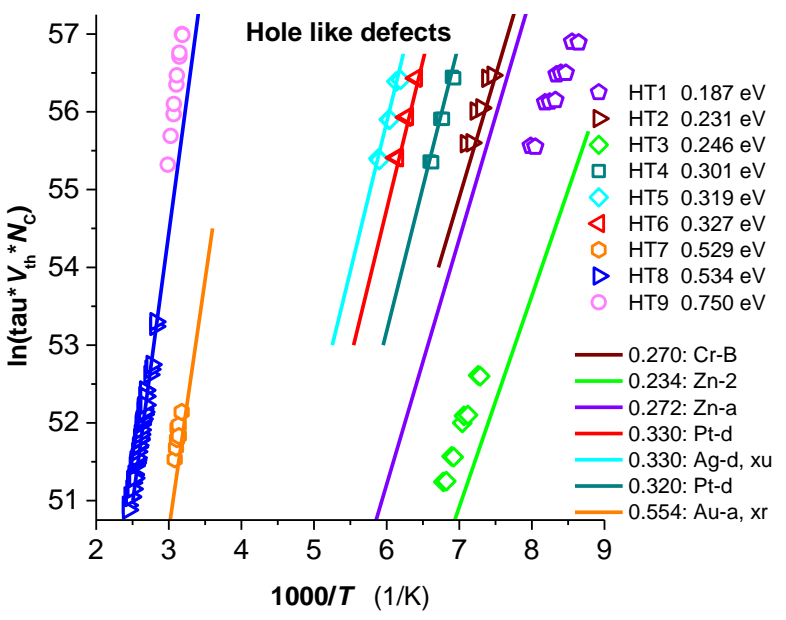

Figure 6: The Arrhenius plot of hole-like defect

During the DLTFS study of structure Stress 2, a significant effect of repeated measurements - thermal and electrical stress on the measured DLTFS signal - was observed (Figure 7). At the same time, the relaxation of the sample is confirmed. Figure 7 shows the DLTFS signal labelled Meas 1, and the DLTFS signal labelled Meas 3. These measured signals are almost identical. The time between the two measurements was 48 hours.

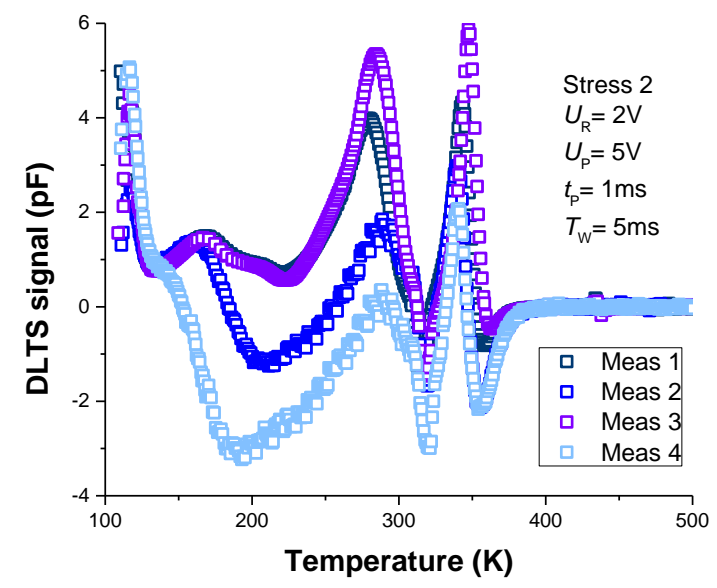

Figure 7: The impact of repetitive DLTFS measuring process measured Arrhenius plot of hole-like defect 


\begin{tabular}{llll}
\hline $\begin{array}{lll}\text { Defect } \\
\text { Name }\end{array}$ & $\begin{array}{l}\text { Energy } \\
\Delta E_{\mathrm{T}}(\mathrm{eV})\end{array}$ & $\begin{array}{l}\text { Cross-section } \\
\sigma_{\mathrm{T}}\left(\mathrm{cm}^{2}\right)\end{array}$ & $\begin{array}{l}\text { Comparison; } \\
\text { references }\end{array}$ \\
ET1 & 0.126 & $7.81 \times 10^{-18}$ & $0.18: \mathrm{VO}[16]$ \\
ET2 & 0.188 & $3.55 \times 10^{-15}$ & $0.180: \mathrm{V}-\mathrm{a}[17]$ \\
ET3 & 0.322 & $8.52 \times 10^{-15}$ & $0.300: \mathrm{Pt}[18]$ \\
ET4 & 0.405 & $7.72 \times 10^{-16}$ & $0.430: \mathrm{Ni}-\mathrm{a}[18]$ \\
ET5 & 0.509 & $4.79 \times 10^{-15}$ & $0.510: \mathrm{Ag}-\mathrm{a}[18]$ \\
& & & $0.510: \mathrm{Mn}(\mathrm{s})[19]$ \\
& & & \\
HT1 & 0.187 & $2.48 \times 10^{-17}$ & $0.234: \mathrm{Zn}$, \\
& & & $0.272: \mathrm{Zn},[20]$ \\
HT2 & 0.231 & $1.39 \times 10^{-16}$ & $0.270: \mathrm{Cr}-\mathrm{B}[21]$ \\
HT3 & 0.246 & $9.84 \times 10^{-14}$ & $0.234: \mathrm{Zn} \mathrm{[20]}$ \\
HT4 & 0.301 & $7.81 \times 10^{-15}$ & $0.320: \mathrm{Pt}-\mathrm{d}[22]$ \\
HT5 & 0.319 & $2.55 \times 10^{-15}$ & $0.330: \mathrm{Ag}-\mathrm{d}, \mathrm{xu}$ \\
& & & {$[23]$} \\
HT6 & 0.327 & $1.10 \times 10^{-14}$ & $0.330: \mathrm{Pt}-\mathrm{d}[22]$ \\
HT7 & 0.529 & $6.50 \times 10^{-15}$ & $0.554: \mathrm{Au}-\mathrm{a}, \mathrm{xr}$ \\
& & & {$[21]$} \\
HT8 & 0.534 & $3.08 \times 10^{-15}$ & $0.599: \mathrm{Zn}-\mathrm{aa}[20]$ \\
HT9 & 0.750 & $1.81 \times 10^{-13}$ & $0.599: \mathrm{Zn}-\mathrm{aa}[20]$ \\
& & &
\end{tabular}

Table 2: Calculated defect parameters with possible referent data

Figures 8 depict compare of measured DLTFS signal of examined structures at the selected measuring conditions. The shape of the measured DLTFS signals shows that electrical stress affects the distribution of electrically active defects significantly below $300 \mathrm{~K}$. This information is highly favourable, as most power devices such as the IGBT operate at room temperature and above. On the other hand, electrical stress significantly multiplies the concentration of defects around a temperature of $225 \mathrm{~K}$ and less. The value of the DLTFS signal capacitance increased from $\sim-3 \mathrm{fF}$ to $\sim-12 \mathrm{fF}$ (Figure $8 \mathrm{~d}$ ), which means that at a temperature of $225 \mathrm{~K}$, there was a fourfold increase in the concentration of defects after electrical stress.

However, the interaction between the majority and minority responses in the range from 300 to $350 \mathrm{~K}$ made it difficult to determine the defect parameters. If there are two defects in the same temperature range, one is electron-like and the second is hole-like, the emission process interacts with each other. When the voltage is reduced to reverse bias after applying the filling pulsed UP DLTFS signal passes from one type of defect to another type through zero (Figure 8 a) in DLTFS spectrum, which indicates interaction of these processes. The peak that we see in the DLTFS spectrum as a defect is the sum of these emissions at a given temperature, which distorts the parameters of the actual defect. Therefore, emission and capture processes at $350 \mathrm{~K}$ are a significant challenge for the DLTFS evaluation of measured spectra. Further research will be devoted to this problem.
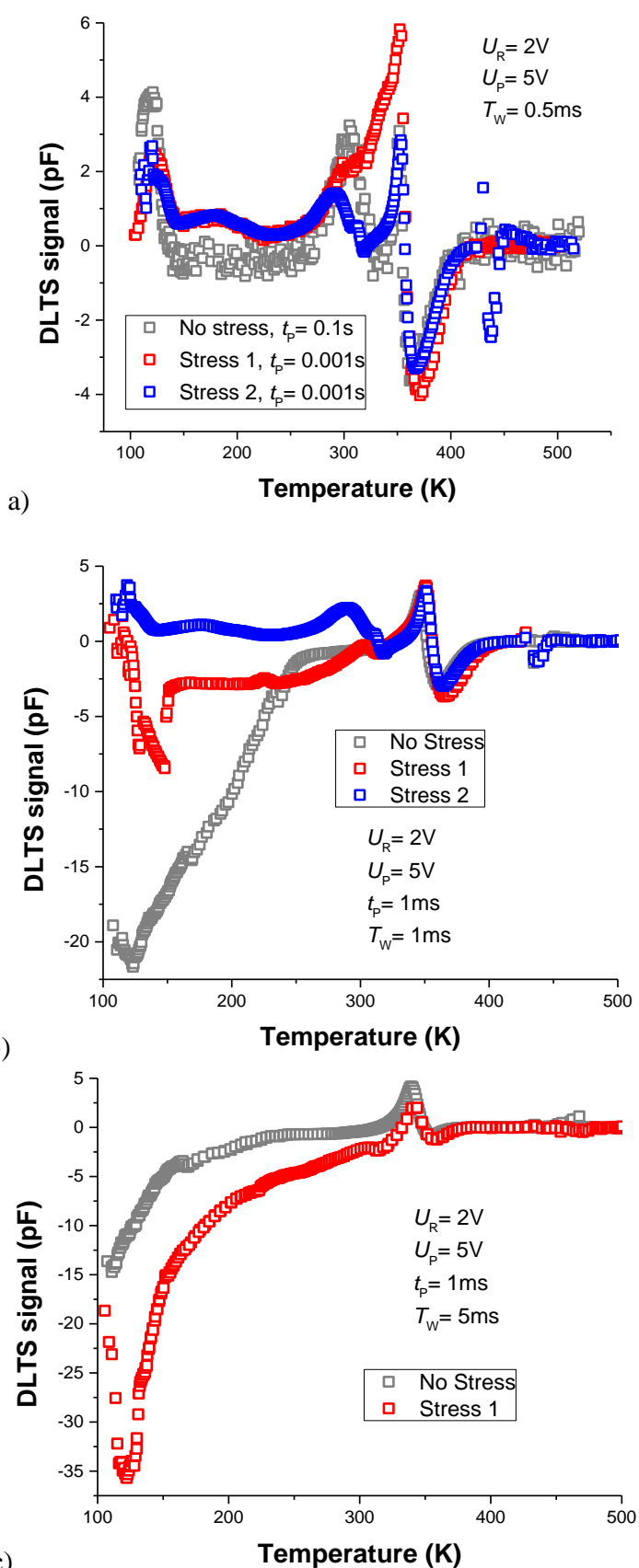

c)

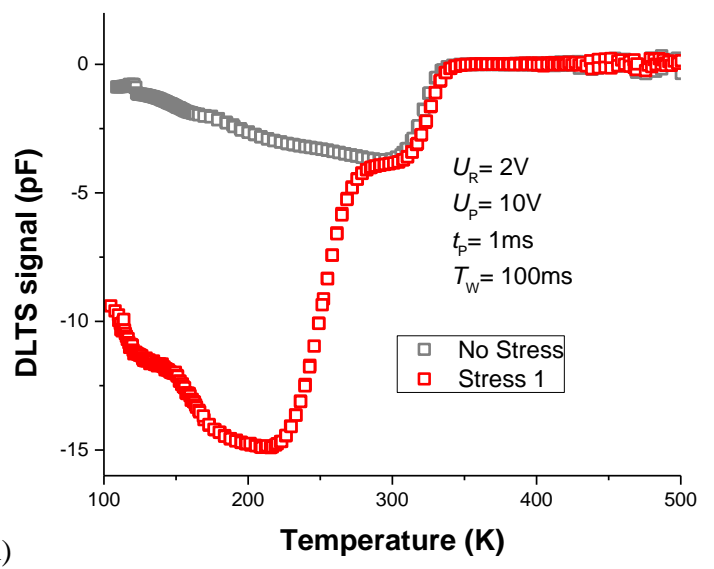

Figure 8: Compare of measured DLTFS signal of examined structures at the special measuring conditions 


\section{CONCLUSION}

Power semiconductors are needed in all stages of energy conversion: generation, transmission, and use. More efficient silicon-based semiconductors devices applied in mobility, industry, and grid make a significant contribution towards reducing carbon dioxide emissions in spite of the world's growing energy needs. IGBT power transistors have an irreplaceable role in power electronics circuits.

This paper deals with the investigation of the distribution of electrically active defects in $1200 \mathrm{~V}$ silicon-based trench gate/field-stop IGBTs by the method of Fourier deep level transient spectroscopy. These power IGBTs were prepared by the sixth generation trench stop IGBT technology. These structures were exposed to electrical stress: pulse width $3 \mu \mathrm{s}$, drain voltage $600 \mathrm{~V}$, the gate voltage $15 \mathrm{~V}$, current $100 \mathrm{~A}$ and number of pulses 200 thousand. Attention is focused on the analysis of the influence of electrical stress on the distribution of defects in the investigated structures.

Five electron-like deep energy levels and nine hole-like deep energy levels were identified. The presence of unintentional impurities like zinc, platinum, gold, etc. and emissions from structural imperfections was confirmed. A significant increase of the defect concentration after electrical stress in the temperature range of 120 to $225 \mathrm{~K}$ has been detected. Electrical stress did not affect the defect concentration above temperature $300 \mathrm{~K}$.

The investigated silicon-based IGBT shows exceptional quality. These are silicon-based power devices that are extremely well mapped, and at the same time, due to the precision of the production technology, silicon is extremely pure, as evidenced by capacitance values corresponding to the maxima of measured DLTFS signals. Very little influence of electrical stress on the distribution of electrically active defects in IGBTs in the area of working temperatures was confirmed.

\section{ACKNOWLEDGEMENTS}

This project has received funding from Power2Power project. Power2Power is a European co-funded innovation project on Semiconductor Industry. The project receives grants from the European H2020 research and innovation program, ECSEL Joint Undertaking, and National Funding Authorities from eight involved countries under grant agreement No. 826417. The participating countries are Austria, Finland, Germany including the Free States of Saxony and Thuringia, Hungary, the Netherlands, Slovakia, Spain and Switzerland. This work was also supported by Grants VEGA 1/0727/19 supported by Ministry of Education, Science, Research and Sport of Slovakia.

\section{REFERENCES}

[1] Lutz, J.: Semiconductor Power Devices as Key Technology for a Future Sustainable Society Power Devices State of the Art and Future Trends, Power Electronic Components and their Applications 2017; 7. ETG-Symposium (Bad Nauhiem, 2017), 7-20

[2] Power2Power: The next-generation of silicon-based power solutions in mobility, industry and grid for sustainable decarbonisation in the next decade. ECSEL Joint Undertaking [online]. Brussels Belgium, 2017, 1.6.2019 [cit. 2021-7-12]. https://www.ecsel.eu/projects/power2power

[3] Europe leads the global clean energy transition: Commission welcomes ambitious agreement on further renewable energy development in the EU. European Commission [online]. 14 June 2018 Technical Report; European Commission: Brussels, Belgium, [cit. 2021-7-12]. https://ec.europa.eu/energy/news/europe-leads-global-cleanenergy-transition-commission-welcomes-ambitiousagreement-further_nl

[4] Baliga, B. J. Semiconductors for high-voltage, vertical channel field-effect transistors. Journal of Applied Physics [online]. 1982, 53(3), 1759-1764

[5] Chow, T. Paul and Guo Z. GaN smart power devices and integrated circuits. Wide Bandgap Semiconductor Power Devices [online]. Elsevier, 2019, 2019, s. 151-208 [cit. 20217-12]. doi:10.1016/B978-0-08-102306-8.00005-8

[6] Amano, H, et al. The $2018 \mathrm{GaN}$ power electronics roadmap. Journal of Physics D: Applied Physics [online]. 2018, 51(16) [cit. 2021-7-12]. doi:10.1088/1361-6463/aaaf9d

[7] Baliga, B. J. IGBT: The GE Story [A Look Back]. IEEE Power Electronics Magazine [online]. 2015, 2(2), 16-23 doi:10.1109/MPEL.2015.2421753

[8] Baliga, B. J. Social impact of power semiconductor devices (Invited Paper). In: 2014 IEEE International Electron Devices Meeting [online]. IEEE, 2014, 2014, 2.1.1-2.1.4 [cit. 2021-7-12]. doi:10.1109/IEDM.2014.7046963

[9] Chmielus, S. Reaching best performance for your frequency inverter with $\mathrm{Si}$ or $\mathrm{SiC}$ power switches [online]. 24 September 2020, 1-36 [cit. 2021-7-12]. https://www.rutronik.com/fileadmin/Rutronik/Specials/Digital SensorTest/2020.09.24-IFX session-frequency inverter.pdf

[10] Deen, M. and Pascal F. Electrical Characterization of Semiconductor Materials and Devices. KASAP, S. and P. CAPPER. Springer Handbook of Electronic and Photonic Materials. Springer US, pp. 453-481, 2017, 1406,

[11] Lang D. V.; Deep level transient spectroscopy: A new method to characterise traps in semiconductors, Journal of Applied Physics 45, 1974, p.3023

[12] Schroder, D. K. Semiconductor material and device characterisation. 3rd ed. Hoboken, N.J.: Wiley, c2006, xv, 779. ISBN 9780471739067 
[13] Kosa, A., Beata Sciana, B. and Stuchlikova, L. Reliability improvement of electrically active defect investigations by analytical and experimental deep level transient: Fourier spectroscopy investigations. Journal of Electrical Engineering [online]. 2019, 70(7), 27-35 [cit. 2021-7-12]. doi:10.2478/jee2019-0038

[14] Weiss S., Kassing R.; Deep Level Transient Fourier Spectroscopy (DLTFS) - A technique for the analysis of deep level properties, Solid-State Electronics 31, 1988, pp.1733-1742.

[15] Application Note AN-983: IGBT Characteristics [online]. July 2012, 1-16 [cit. 2021-7-12]. https://www.infineon.com/dgdl/Infineon-

IGBT_Characteristics-AN-v01_00-

EN.pdf?fileId=5546d462533600a40153559f8d 921224

[16] Corbett, J.W. et al: Defects in Irradiated Silicon. II. Infrared Absorption of the Si-A Center, Physical Review, 121, 1961, 1015-1022

[17] Kawahara, H. et al: Vanadium-Related Deep Levels in nSilicon Detected by Junction Capacitance Waveform Analysis, Japanese Journal of Applied Physics, 31, 1992, 87-89

[18] Benton, J.L. and Kimerling L.C.: Capacitance Transient Spectroscopy of Trace Contamination in Silicon, Journal of The Electrochemical Society, 129, 1982, 2098-2101

[19] Nakashima, H. and Hashimoto, K.: Deep impurity levels and diffusion coefficient of manganese in silicon, Journal of Applied Physics, 69, 1991, 1440-1446

[20] Weiss, S. et al: The electrical properties of zinc in silicon, Applied Physics A, 50, 1990, 151-156
[21] Graff, K.: Metal Impurities in Silicon-Device Fabrication, Springer, 1995

[22] Stöffler, W. and Weber, J.: Influence of hydrostatic pressure on the platinum levels in silicon, Physical Review B, 33, 1986, 8892

[23] Pandian, V. and Kumar, V.: Silver related deep levels in silicon, Physica Status Solidi A, 109, 1998, 273-278

[24] Fukuoka, N., Yoneyama, M., Honda and Atobe, K.: In: Appl. Phys., 32, 1993, no. 5A, pp. 2059-2062

Addresses of the authors

Jakub Drobny, Institute of Electronics and Photonics, Slovak University of Technology in Bratislava, Ilkovicova 3, 812 19, Bratislava, Slovakia, jakub.drobny@stuba.sk

Juraj Marek, Institute of Electronics and Photonics, Slovak University of Technology in Bratislava, Ilkovicova 3, 812 19, Bratislava, Slovakia, juraj.marek@stuba.sk

Ales Chvala, Institute of Electronics and Photonics, Slovak University of Technology in Bratislava, Ilkovicova 3, 812 19, Bratislava, Slovakia, ales.chvala@stuba.sk

Jan Faraga, Institute of Electronics and Photonics, Slovak University of Technology in Bratislava, Ilkovicova 3, 812 19, Bratislava, Slovakia, xfaraga@stuba.sk

Martin Jagelka, Institute of Electronics and Photonics, Slovak University of Technology in Bratislava, Ilkovicova 3, 812 19, Bratislava, Slovakia, POWERTEC, s.r.o, Drotárska 19a, 811 04, Bratislava, Slovakia, martin.jagelka@stuba.sk,

Lubica Stuchlikova, Institute of Electronics and Photonics, Slovak University of Technology in Bratislava, Ilkovicova 3, 812 19, Bratislava, Slovakia, lubica.stuchlikova@stuba.sk 